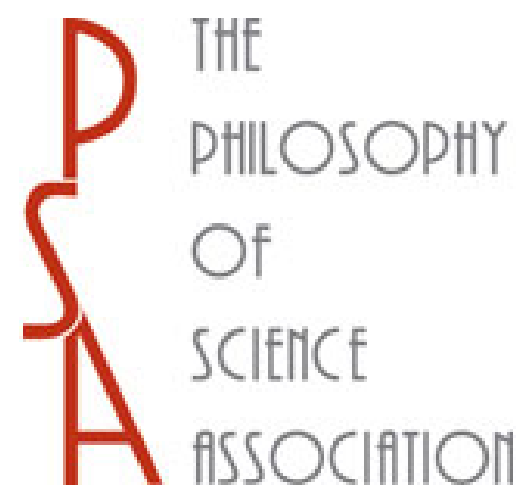

Do We Need a Device to Acquire Ethnic Concepts?

Author(s): Adam Hochman

Source: Philosophy of Science, Vol. 80, No. 5 (December 2013), pp. 994-1005

Published by: The University of Chicago Press on behalf of the Philosophy of Science Association

Stable URL: http://www.jstor.org/stable/10.1086/673896

Accessed: 09/01/2014 07:15

Your use of the JSTOR archive indicates your acceptance of the Terms \& Conditions of Use, available at http://www.jstor.org/page/info/about/policies/terms.jsp

JSTOR is a not-for-profit service that helps scholars, researchers, and students discover, use, and build upon a wide range of content in a trusted digital archive. We use information technology and tools to increase productivity and facilitate new forms of scholarship. For more information about JSTOR, please contact support@jstor.org. 


\title{
Do We Need a Device to Acquire Ethnic Concepts?
}

\author{
Adam Hochman*†
}

Francisco Gil-White argues that the ubiquity of racialism - the view that so-called races have biological essences - can be explained as a by-product of a shared mental module dedicated to ethnic cognition. Gil-White's theory has been endorsed, with some revisions, by Edouard Machery and Luc Faucher. In this skeptical response I argue that our developmental environments contain a wealth, rather than a poverty of racialist stimulus, rendering a nativist explanation of racialism redundant. I also argue that we should not theorize racialism in isolation from racism, as value judgments may play a role in essentialist thinking about the 'other'.

1. Introduction. Thinking racially is second nature to us. Or is it first nature? The former is undoubtedly true. Even when scientists and philosophers argue for the illegitimacy of human racial divisions, they find it necessary to use racial concepts - although they do tend to confine them within scare quotes. ${ }^{1}$ The latter is not plausible. It is unlikely that our early ancestors had sustained contact with morphologically divergent human groups, as they tended to be geographically distant from one another. As a result, it is unlikely that we have an adaptation for racial cognition. In this sense, thinking racially is not in our 'first nature'.

Another alternative has emerged in the literature. While we do not have what evolutionary psychologists would call a 'race module', several authors have argued that we have another specialized cognitive device, which fa-

\footnotetext{
*To contact the author, please write to: Department of Philosophy, University of Sydney, Quadrangle A14, NSW 2006, Australia; e-mail: adam.hochman83@gmail.com.

$\dagger$ I would like to thank Paul Griffiths and Pierrick Bourrat for their helpful comments on an earlier draft. This research was supported by the Australian Research Council's Discovery Projects funding scheme DP0878650 and an Australian Postgraduate Award through the University of Sydney.

1. The illegitimacy of racial taxonomy is assumed throughout this article. For arguments against racial naturalism, see Hochman (2013).

Philosophy of Science, 80 (December 2013) pp. 994-1005. 0031-8248/2013/8005-0025\$10.00 Copyright 2013 by the Philosophy of Science Association. All rights reserved.
} 
cilitates racial cognition (Hirschfeld 1998; Gil-White 2001; Kurzban, Tooby, and Cosmides 2001; Machery and Faucher 2005a). While these authors differ on the specifics, they all argue that racial cognition is the by-product of a mental mechanism that evolved for some other purpose.

This article offers a skeptical response to Gil-White's theory about the origins and nature of racial cognition. His proposal, that racial cognition is the by-product of a module dedicated to ethnic cognition, has been endorsed (with some revisions) by Machery and Faucher (2005a), who call this proposed module an ethnic concepts acquisition device (ECAD). The ECAD is conceived as an exaptation - a once adaptive extension-of Scott Atran's (1998) hypothesized folk-biology module.

My central argument is that both the folk-biology module and the ECAD are susceptible to a 'wealth of the stimulus' argument (Sterelny 1995). The more familiar 'poverty of the stimulus' argument suggests that a trait could not be learned, given the lack of stimulus in the developmental environment, without the help of specialized cognitive equipment. Wealth of the stimulus arguments, on the contrary, can be persuasive arguments against modularity because they suggest that there is sufficient stimulus in the developmental environment to account for the learning of a trait, rendering specialized cognitive equipment - in this case the folk-biology module and the ECADexplanatorily redundant.

Gil-White (2001) and also Machery and Faucher (2005a) focus on racialism - the view that 'races' have biological essences - rather than racism, which adds a (typically negative) value judgment. I argue that this conceptual isolation is a mistake. Racialism cannot be historically separated from racism, and value judgments may play a role in essentialist thinking about the 'other'.

2. Put Down That Ethnic Concepts Acquisition Device! An 'ethnic concepts acquisition device' sounds like something out of a science fiction novel. In this section I look at the evidence in its favor. I re-create the argument for the exaptation step by step, so this section also serves as a summary of the evolutionary approach to racialism proposed by Gil-White (2001) and largely endorsed by Machery and Faucher (2005a; see their 2005b for critical comments).

To begin, there is evidence that during human evolution our ancestors banded together not only in kin-based groups and small-scale coalitions but also in large tribes or 'ethnies' (Bettinger 1991, 203-5; Richerson, Boyd, and Henrich 2003). Richerson, Boyd, and Henrich warn that this is "controversial because the archaeological record permits only weak inferences about social organization and because the spectrum of social organization in ethnographically known hunter-gatherers is very broad" (369). However, while there may be no archetypal early human society, studies indicate that 
small groups or bands often aggregated together on a seasonal basis, and that these assemblages differed culturally from region to region (Conkey 1980; White 1982, 176).

Ethnies are characterized as cultural units - their members sharing culturally transmitted beliefs, preferences, and norms. These characteristics are often ethnie specific and distinguish ethnies from each other. Ethnies are also understood to practice normative endogamy, the norm of keeping reproductive relations within the group. As a historical claim about the social organization of early ethnies, this is difficult to confirm. Proponents of the ECAD support this claim by reference to extant tribes such as the Nuer in Sudan and the Iroquois in North America, who illustrate this form of social organization (Machery and Faucher 2005a). However, normative endogamy is not the same as practiced endogamy. The relationship between the Nuer and the neighboring Dinka, for instance, is as much characterized by persistent feudalism as it is by a long history of intermarriage and assimilation (Johnson 1982). The degree to which (and the conditions under which) early ethnies were normatively endogamous remains an open question.

Nevertheless, navigating the ethnic world must have been - it seems safe to infer-an important aspect of the lives of our distant ancestors. Knowledge of one's own culture and customs, and the ability to distinguish between members of one's own ethnic group and another, would have been of great consequence to those enmeshed in the ethnic world. Gil-White, Machery, and Faucher believe that this form of social organization created an adaptive pressure on our ancestors. Drawing on the work of Atran (1998), they propose that our folk biology was exapted and applied to ethnies. Of course a trait is only an exaptation if the original trait was once an adaptation for another purpose. Gil-White, Machery, and Faucher, following Atran, believe that our folk biology is influenced by a "folk-biology module" (Atran 1998, 556). This module, argues Atran, causes us to privilege the generic species level in our explanations of biological phenomena and also to assume that the similarities of species members are explained by initially imperceptible species-specific essences. 'Essence', in this context, means something like 'underlying causal nature'.

Evidence for the folk-biology module comes from a survey that Atran (1998) administered to ecologically inexperienced North American university students and ecologically experienced Mayan Itzaj. He found that both prefer to make biological inferences at the generic species rank (e.g., vulture), rather than the level of life-form (e.g., bird), the folk-specific level (e.g., black vulture), or the varietal level (e.g., redheaded black vulture). While North American university students perceptually discriminate lifeforms such as 'tree' much more readily than species such as 'elm' or 'beech' (Coley, Medin, and Atran 1997), they believe that inferences about trees 
(e.g., regarding susceptibility to disease) should be made at the species level. Atran explains this cross-cultural similarity by reference to a shared "folkbiology module," which "enables humans to apprehend the biological world spontaneously as a partitioning into essence-based generic species" (1998, 555). If folk biology were enabled by domain-general processes alone, it would be hard to explain, suggests Atran, why people across cultures believe that the underlying causal natures (or 'essences') of biological phenomena cluster at the generic species level, making this the preferred level for induction.

Gil-White, followed by Machery and Faucher, proposes the following adaptive scenario. The folk-biology module was ripe for exaptation. Species and ethnies share the following characteristics: they have distinctive morphologies (in ethnies, dress) and distinctive behaviors, they are endogamous (at least normatively), and membership is conferred by descent (Machery and Faucher 2005a, 1212). Thinking about ethnies as if they were species was adaptive, claims Gil-White, because it enabled inductive inferences without "too much costly interaction with out-group members" $(2001,515)$. Hence our ethnic cognition evolved as an extension of the folkbiology module.

This adaptive - or exaptive - scenario is supported by a questionnaire study Gil-White administered to 100 Mongolian Torguud and Kazakh seminomadic pastoralists. While living in the same environment, and belonging to the same social class, these two ethnic groups are territorially separated. The questionnaire reads as follows:

1. If the father is Kazakh and the mother Mongol, what is the ethnicity of the child?

2. The father is Kazakh, the mother Mongol, but everybody around the family is Mongol and the child has never even seen a Kazakh outside of the father. The child will learn Mongol customs and language. What is the ethnicity of this child?

3. A Kazakh couple has a child that they don't want. They give it in adoption to a Mongol couple when the child is under a year old. Around the Mongol family there only are Mongols, and the child grows up never meeting or seeing a single Kazakh. He is never told of the adoption and thinks that his biological father and mother are the Mongol adopters. He grows up learning Mongol customs and language. What is the ethnicity of this child? (Gil-White 2001, 522)

For Torguuds and Kazakhs ethnic inheritance is patrilineal. Consistent with paternal-based ethnic descent, 100\% of the subjects in Gil-White's 1997 study, and $90 \%$ of the subjects in his 1998 study, claimed - in response to 
the first question - that the child would be Kazakh (Gil-White 2001). To the second question, $83 \%$ and $80 \%$, respectively, answered that the child would be Kazakh. In response to the third question, 59\% in 1997 and 76\% in 1998 claimed that the child would be Kazakh. Gil-White characterizes those who answered the three questions Kazakh, Kazakh, Kazakh as strict essentialists, or 'hard primordialists'. He argues that these results demonstrate an essentialist bias in ethnic thinking which cannot be explained by reference to descent-based ethnicity alone. The subjects appear to believe in some internal 'essence' that causes ethnicity and is quite impervious to rearing environments.

Gil-White claims that we are predisposed to interpret cultural phenotypic differences, like those displayed by ethnies, as signals of underlying essences. "It is also plausible," argues Gil-White, "that dramatic differences in skin color, hair type, etc.- - which would have been absent between neighbors in the ancestral environment but are common today because of modern migrations, colonialism, etc. - are interpreted by our brains as ethnic diacritics. In other words, we essentialize races because we mistakenly 'think' they are ethnic groups. We thus process 'races' as ethnies even though not by the longest stretch of the imagination can they be characterized as representing norm or behavioral boundaries of any kind, which is the original reason for exapting the living-kinds module" $(2001,534)$. It is this exaptation that Machery and Faucher identify as the ECAD. This completes the argument: from folk-biology module to ECAD, to its unfortunate misfiring, facilitating racial, and racist cognition. We think racially not because there are in fact human races, or subspecies, but because the ECAD mistakenly 'processes' racialized groups as if they were ethnies. We treat 'races' as if they were ethnies, and we treat ethnies as if they were species.

3. How Biological Is Essentialism? The biggest threat to the evolutionary theory of racialism sketched above is the possibility that the empirical results appealed to have non-nativist explanations. In this section I argue that this threat is real, and I offer a nonnativist interpretation of Atran's findings. I leave off discussing the ECAD until the following section, but it is important to note that without the folk-biology module as an adaptation, the ECAD loses its footing as a possible exaptation. First, however, I will consider the claims about universality tentatively put forward by both Atran and Gil-White.

Atran (1998) and Gil-White (2001) both argue for human universals based on evidence from two cases: for Atran, Michigan university students and Mayan Itzaj; for Gil-White, the neighboring Torguuds and Kazakhs. However, two instances do not make a trend, let alone a universal. "My problem with Atran's target article," writes Barbara Saunders, "is that it is question begging. Although it sets out to show empirically that in every human soci- 
ety people think about plants and animals in the same special way, Atran takes this as his a priori premise from the outset" $(1998,587)$. Responding to Gil-White's (2001) paper (which was also a target article), Tim Ingold suggests, "if it takes only two positive instances to confirm the existence of a universal, then by the same token it would take only one negative instance to refute it" (542). Indeed, there are many cultures in which ethnicity is not something you are born with but rather something that you learn, something you perform (Fox 1987; Bloch 1993; Astuti 1995; Carsten 1995). Atran and Gil-White's claims about universality should be considered carefully against the available evidence.

Even when a trait is widespread, we cannot thus infer that it was the ancestral state. The 'majority rules' heuristic can be misleading when the trait in question is not present in basal lineages (see Gray, Greenhill, and Ross 2007). In any case we should be wary of easy arguments from the universality of a trait to the existence of an adaptation dedicated to that trait. Just as not everything that has evolved is universal, not everything that is universal has evolved. Even if Atran has discovered a universal tendency to make inferences at the generic species level, this may be the joint outcome of motivated learners living in a similarly structured, or 'universal', environment. Indeed, such environmental structure is presupposed by Atran's argument. James Maffie, in his response to Atran, invites us to suppose that there is enough environmental structure to enable a folk-biology module to evolve: "If this is so," he points out, "then there is also enough environmental structure for people in all cultures to generate this taxonomy empirically without the need for a domain-specific innate structure" (Maffie 1998, 583). Hence the inference from universality to innateness by appeal to natural selection is not supported by Atran's findings.

To formalize Maffie's argument, we have a wealth, rather than a poverty, of biological stimulus. Nativist theories are only compelling when learning cannot account for the relevant data. However, the fact that cats beget cats, and dogs beget dogs, and that they somehow transmit catlike natures and doglike natures, is not ecologically opaque. Only in the most impoverished urban environment is it imaginable that such facts of life could go unrecognized. Nor is it surprising that 'ecologically inexperienced' North American students prefer to make biological inductions at the species level, even though they are not good at actually naming species. What industrialized people lack in hands-on ecological knowledge, they partly make up for in formal education and exposure to the information-soaked medias. The Itzaj, on the other hand, may prefer to make generalizations about species because the species level is simply the most practical level for induction. What science tells the North American students, experience tells the Itzaj.

Some of the most compelling arguments against the folk-biology module have been advanced, surprisingly, by proponents of evolutionary approaches 
to racial cognition. Susan Gelman and Lawrence Hirschfeld (1999) have argued that the emergence of essentialism in childhood is a single conceptual bias and that we have no good reason to believe that folk biology is its proper domain. As they note, people also attribute hidden essences to gender (Taylor 1996), as well as to personality (Gelman 1992). Machery and Faucher are also somewhat skeptical of nativist accounts of folk biology. They argue that "universal folk biological beliefs may simply be true beliefs that are easily learned either by individuals or by cultures" $(2005 \mathrm{~b}, 1028)$. Again, we have a wealth of biological stimulus.

Machery and Faucher, while endorsing most of Gil-White's ideas, "believe that we have no evolved disposition to entertain most of our folk biological beliefs" (2005a, 1213). Citing Atran and others they write, "there is some convincing evidence that we are disposed to think of species in a hierarchical way" and that we "may also have evolved to expect species-specific properties" (2005b, 1028). However, they warn that our evolved folk biology may consist of little more: "Particularly, essentialism - that is, a belief in essences - may be culturally transmitted and culturally specific" (1028). This is a self-defeating argument. It is the belief in essences that is supposed to explain why we "expect species-specific properties." And we are meant to prefer the generic species level for induction because it is the locus of the essences that cause these properties. Essentialism is, one might say, essential to the folk-biology module, and hence to the ECAD.

4. How Essential Is Biologism? Machery and Faucher call the belief that so-called racial properties are transmitted at birth and are constant over life biologism. By 'biologism' I mean something different: the tendency to give phenomena biological explanations. In this section I argue against this tendency in relation to essentialist thinking about ethnies and racialized groups.

To begin, note that there are some incongruities in the argument leading to the ECAD. For instance, all of Gil-White's respondents accepted the terms of his questions: nobody said, "It is as impossible for a Kazakh and a Mongol to have offspring as it is for marmot to mate with a house-cat." If we indeed 'process' ethnies as if they were species, it should be impossible for members of different ethnies to have children. Gil-White replied to this criticism (leveled by about half of his respondents) by pointing out that if we consider interethnic marriage as akin to the mating of donkeys with horses, this worry evaporates. He hypothesizes that we spontaneously view such matings as unnatural, but possible, and that we see interethnic couplings the same way. However, this is purely conjectural, and even Machery and Faucher $(2005 b, 1029)$ express their doubts about this claim.

Another problem is that not all of the respondents to Gil-White's questionnaire were essentialists. Many were not, and this remains unexplained. 
The evidence actually indicates that essentialism about ethnies comes in degrees. This is a significant finding, but Gil-White seems to treat it as noise. For instance, he recounts a conversation with his guide, who had previously maintained strictly nonessentialist beliefs, in which he admitted that members of another ethnic group could cast curses and that this particular ability was inherited. 'Scratch a soft circumstantialist, and watch a hard primordialist bleed', appears to be the lesson we are meant to take from this anecdote. But here the analogy with species essentialism is being stretched quite far. GilWhite calls his theory The Ugly Duckling hypothesis, for obvious reasons. However, as David Laitin points out, in The Ugly Duckling the swan "proves itself to be a genuine swan, not an almost-duck that has retained an innate capacity to do perhaps one unique swanlike thing" (Gil-White 2001, 543). If we are predisposed to see ethnies as species, we see them as very odd species indeed.

Gil-White recounts another incident when a large group of old Kazakh men at a party took interest in his work, and they turned out to be "not at all essentialist" $(2001,528)$. Afterward, a circle of young men protested that the old folk were wrong. Our attention is then diverted to the opinions of the youngsters, but, as Ma Rong points out, "No explanation is given for the reported difference in ethnic categorizing between older and younger generations. If we consider the political/ideological environments in which they grew up, the picture becomes clearer. The older generation grew up with the communist ideology that class was more essential than ethnicity. The younger generation grew up under a new nationalism that strongly emphasizes the essences of ethnies" (544). Both essentialism and nonessentialism, Rong suggests, have political explanations.

Machery and Faucher (2005b) also argue that nonessentialism needs to be directly explained. They suggest that the ECAD predisposes us to learn to be essentialists. It primes us to learn racial concepts, for instance, but concepts of race are culturally transmitted, and their acceptance, they argue, will depend on factors such as conformism and prestige-dependent imitation (see Machery and Faucher 2005a). Machery and Faucher (2005b) criticize GilWhite for explaining away nonessentialist beliefs. However, they may be guilty of quite the opposite - explaining away essentialism. Even if essentialist thinking was adaptive for our distant ancestors, we may not have evolved an adaptation in its service. A strictly adaptationist position is question begging: how and why people tend to essentialize others is what we are trying to understand.

Explaining the essentialism involved in racialism raises its own issues. As Ian Hacking points out, "There are two strands of thought in the human sciences, the one universalist, the other emphasizing contingencies. They seldom harmonize" $(2005,116)$. Machery and Faucher $(2005 \mathrm{a})$ call this the 
integration challenge, and they observe that universalist and contingent theories of racialism face a symmetrical problem. Universalist theories have to account for diversity in racialism among people, across cultures, and throughout history. Contingent theories must explain the ubiquity of racialism. Machery and Faucher attempt to solve the integration challenge by arguing that while the concept of race is socially learned and thus varies, the ECAD produces a universal cognitive bias toward racialism.

I will only consider Hacking's explanation of the ubiquity of racialismand not its vicissitudes - as this is what is at issue here. Hacking appeals to Cornel West's $(1982,47-65)$ genealogy of racism. West is interested in the following paradox. How could racist ideologies and slavery arise at the same time and place as philosophies promoting individual and human rights, justice, and equality? The answer lies in the fact that equality was not conceived to be between different but equally appealing alternatives. Equality was between those who were essentially the same. By the middle of the nineteenth century 'races' were understood as essentially different, so there was no imperative to treat them all equally (47-65). And where colonialism went, racialism followed. When Machery and Faucher argue that "the social constructionist approach [to racialism] does not explain the commonalities between the culture-specific concepts of race, e.g., the concepts of race in contemporary North America, in nineteenth-century France, in Germany, during the Nazi era, and so on" (2005a, 1209-10), they forget that historians are now largely in agreement that the concept of race is a modern invention. We should expect commonalities in the examples listed above.

It is interesting that from Hacking's point of view, racialism derives from the historical, the contingent, whereas for Gil-White, Machery, and Faucher it is a consequence of our universal nature. For Hacking, then, an evolutionary, universalist approach to racialism suffers from explanatory redundancy. As Hacking argues, "Well-intentioned television programming for children constantly emphasizes that the characters, even if they are not human, are of different races. From infancy, children watch television cartoons that show, for instance, a happy black family playing with a happy white family. The intended message is that we can all get on well together. The subtext is that we are racially different, but should ignore it. Experimenters discover that small children expect parents of any color to have children of the same color. Is that proof of innate essentialism or of the efficacy of television?" (2005, 112). This can be formalized as a wealth of the stimulus argument. We need not hypothesize a module that, in some sense, programs children to attend to race, when our culture has the same effect. Unfortunately, there is a wealth, rather than a poverty of racialism, present in nearly every society. As essentialist beliefs are easily learned we have no need to posit an evolved cognitive device for directing our attention toward them. 
Along with Gil-White, Machery, and Faucher, I believe that there is a link between ethnic essentialism and the essentialism involved in racialism. However, I am not convinced that the ECAD is this link. In isolating ethnic essentialism from ethnocentrism (belief in the superiority of one's culture) and racialism from racism, these authors have overlooked the possibility that value judgments play a role in essentialist thinking about the 'other'. For instance, when two groups are in conflict, essentialist beliefs about the rival group can be used to justify differential perceptions (Yzerbyt, Rocher, and Schadron 1997). Similar logic applies to the individual level. As Stephen Frosh explains, "the process of racist thought is one in which unwanted or feared aspects of the self are experienced as having the power to disturb the personality in so damaging a way that they have to be repudiated and evacuated or projected into the racialized other, chosen for this purpose both because of preexisting social prejudices and because, as a category of fantasy, racial 'otherness' can be employed to mean virtually anything" (2002, 340). The same is plausibly true of ethnocentric thought. Essentialism may play a key role in the maintenance of in-group out-group boundaries and also in the justification of differential perceptions and treatment between in-group and out-group members. By isolating ethnic essentialism from ethnocentrism and racialism from racism, Gil-White, Machery, and Faucher have overlooked the possible motivational factors behind essentialist thinking about the 'other'. Common motivational factors, and not an evolved cognitive structure, may explain the ubiquity of ethnic essentialism and racialism.

5. Conclusion. The nativist approach to racialism suffers from an overly zealous form of adaptationism. We can plausibly explain Atran's and GilWhite's data without recourse to nativism. As the ECAD is conceived as an exaptation, it depends on the existence of Atran's folk-biology module. As such, this may be a case of bad empirical bet on top of bad empirical bet. When there is a wealth, rather than a poverty of stimulus, it is especially difficult to maintain nativist hypotheses. Wealth of the stimulus arguments apply to both the folk-biology module and to the ECAD, casting doubt on the nativist approach to ethnic cognition.

Proponents of the ECAD have argued that our innate essentialism predisposed us to racism (Machery and Faucher 2005b, 1011). I have argued that this gets the causality wrong. Historically, racism has gone hand in hand with racialism. Furthermore, the negative value judgments associated with racism, and also ethnocentrism, may play a role in essentialist thinking about the 'other'. What better way to maintain in-group out-group barriers, or to justify differential treatment, than to spread the belief that this ethnic group, or that racialized other, is essentially inferior, essentially aggressive, 
or essentially spell-casting? Unfortunately, essentialist beliefs are pervasive and easily learned: we do not need to be predisposed by an ECAD in order to acquire them. Essentialist thinking may have been fitness enhancing for early ethnies, but we can understand its ubiquity without introducing another device into our heads.

\section{REFERENCES}

Astuti, Rita. 1995. “'The Vezo Are Not a Kind of People': Identity, Difference, and 'Ethnicity' among a Fishing People of Western Madagascar." American Ethnologist 22:464-82.

Atran, Scott. 1998. "Folk Biology and the Anthropology of Science: Cognitive Universals and Cultural Particulars." Behavioral and Brain Sciences 21:547-69.

Bettinger, Robert L. 1991. Hunter-Gatherers: Archaeological and Evolutionary Theory. New York: Plenum.

$\rightarrow$ Bloch, Maurice. 1993. "Zafimaniry Birth and Kinship Theory." Social Anthropology 1:119-32.

$\rightarrow$ Carsten, Janet. 1995. "The Politics of Forgetting: Migration, Kinship, and Memory on the Periphery of the Southeast Asian State." Journal of the Royal Anthropological Institute 1:317-35.

Coley, John, Douglas Medin, and Scott Atran. 1997. "Does Rank Have Its Privilege? Inductive Inferences in Folkbiological Taxonomies." Cognition 63:77-112.

$\rightarrow$ Conkey, Margaret W. 1980. "The Identification of Prehistoric Hunter-Gatherer Aggregation Sites: The Case of Altamira." Current Anthropology 21:609-30.

Fox, James. 1987. "The House as a Type of Social Organization on the Island of Roti." In De la hutte au palais: Sociétés "àmaison” en Asie du sud-est insulaire, ed. Charles Macdonald, 109-31. Paris: CNRS.

$\rightarrow$ Frosh, Stephen. 2002. "The Other." American Imago 59:389-407.

$\rightarrow$ Gelman, Susan A. 1992. "Children's Conception of Personality Traits - Commentary." Human Development 35:280-85.

Gelman, Susan A., and Lawrence A. Hirschfeld. 1999. "How Biological Is Essentialism." In Folkbiology, ed. Douglas Medin and Scott Atran, 403-46. Cambridge, MA: MIT Press.

$\rightarrow$ Gil-White, Francisco (with comments by Tim Ingold, David D. Laitin, Ma Rong, et al.). 2001. "Are Ethnic Groups Biological 'Species' to the Human Brain?” Current Anthropology 42:515-53.

$\rightarrow$ Gray, Russell D., Simon J. Greenhill, and Robert M. Ross. 2007. "The Pleasures and Perils of Darwinizing Culture (with Phylogenies).” Biological Theory 2:360-75.

$\rightarrow$ Hacking, Ian. 2005. "Why Race Still Matters." Daedalus 134:102-16.

Hirschfeld, Lawrence A. 1998. Race in the Making: Cognition, Culture, and the Child's Construction of Human Kinds. Cambridge, MA: MIT Press.

$\rightarrow$ Hochman, Adam. 2013. "Racial Discrimination: How Not to Do It." Studies in History and Philosophy of Biological and Biomedical Sciences 44:278-86.

$\rightarrow$ Johnson, Douglas H. 1982. "Tribal Boundaries and Border Wars: Nuer-Dinka Relations in the Sobat and Zaraf Valleys, c. 1860-1976.” Journal of African History 23:183-203.

Kurzban, Robert, John Tooby, and Leda Cosmides. 2001. "Can Race Be Erased? Coalitional Computation and Social Categorization." Proceedings of the National Academy of Sciences 98:15387-92.

$\rightarrow$ Machery, Edouard, and Luc Faucher. 2005a. "Social Construction and the Concept of Race." Philosophy of Science 72:1208-19.

- 2005b. "Why Do We Think Racially? A Critical Journey in Culture and Evolution." In Handbook of Categorization in Cognitive Science, ed. Henri Cohen and Claire Lefebvre, 1009-33. Amsterdam: Elsevier.

Maffie, James. 1998. “Atran's Evolutionary Psychology: 'Say It Ain't Just-So, Joe.'” Behavioral and Brain Sciences 21:583-84.

Richerson, Peter, Robert Boyd, and Joseph Henrich. 2003. "Human Cooperation." In Genetic and Cultural Evolution of Cooperation, ed. Peter Hammerstein, 357-88. Cambridge, MA: MIT Press. 
$\rightarrow$ Saunders, Barbara. 1998. "What's Empirical about Atran's Taxonomies?” Behavioral and Brain Sciences 21:587-88.

$\rightarrow$ Sterelny, Kim. 1995. “The Adapted Mind.” Biology and Philosophy 10:365-80.

$\rightarrow$ Taylor, Marianne G. 1996. "The Development of Children's Beliefs about Social and Biological Aspects of Gender Differences." Child Development 67:1555-71.

West, Cornel. 1982. Prophesy Deliverance! An Afro-American Revolutionary Christianity. Philadelphia: Westminster.

White, Randall. 1982. "Rethinking the Middle/Upper Paleolithic Transition." Current Anthropology 23:85-108.

Yzerbyt, Vincent, Steve Rocher, and Georges Schadron. 1997. "Stereotypes as Explanations: A Subjective Essentialistic View of Group Perception." In The Social Psychology of Stereotyping and Group Life, ed. Russell Spears, Penelope Oakes, Naomi Ellemers, and S. Alexander Haslam, 20-50. London: Blackwell. 